\title{
Digestibilidade aparente de dietas com níveis crescentes de concentrado em novilhos Brangus e Nelore
}

\author{
[Apparent digestibility of diets with increasing concentrate levels in Brangus and Nellore steers] \\ S.M. Putrino ${ }^{1,5}$, P.R. Leme ${ }^{2}$, S. Luz e Silva ${ }^{1}$, M.Q. Manella ${ }^{3}$, J.C.M. Nogueira Filho ${ }^{2}$, \\ C.G. Lima ${ }^{2}$, G.F. Alleoni ${ }^{4}$ \\ ${ }^{1}$ Zootecnista autônomo \\ ${ }^{2}$ Faculdade de Zootecnia e Engenharia de Alimentos - USP - Pirassununga, SP \\ ${ }^{3}$ Instituto de Zootecnia - São Paulo, SP \\ ${ }^{4}$ Instituto de Zootecnia - Nova Odessa, SP \\ ${ }^{5}$ Bolsista da CAPES
}

\begin{abstract}
RESUMO
Determinou-se a digestibilidade aparente, pela coleta total de fezes, de dietas contendo 20, 40, 60 ou $80 \%$ de concentrado para novilhos Brangus e Nelore. Oito animais, quatro de cada raça, foram utilizados em delineamento quadrado latino $4 \times 4$, com cinco dias de adaptação e cinco dias de coleta de fezes, em cada período. A idade e o peso iniciais dos Brangus e Nelore foram 13 meses e $248 \mathrm{~kg}$ e 30 meses e $403 \mathrm{~kg}$, respectivamente. Houve efeito do nível de concentrado $(\mathrm{P} \leq 0,01)$ sobre os coeficientes de digestibilidade da matéria seca (MS), proteína bruta (PB), extrato etéreo, fibra bruta, fibra em detergente neutro, extrativo não-nitrogenado (ENN), matéria orgânica (MO) e nutrientes digestíveis totais (NDT). A dieta com $80 \%$ de concentrado apresentou maior digestibilidade da MS, PB e NDT. A digestibilidade do ENN e da MO e a ingestão de MS foram diferentes entre raças $(\mathrm{P}<0,05)$; os Brangus tiveram maior ingestão de MS e NDT $(\mathrm{P}<0,01)$. Houve interação entre raças e níveis de concentrado quanto à ingestão de MS e NDT $(\mathrm{P}<0,01)$, com maior ingestão pelos Brangus, nos níveis mais altos de NDT. Os Nelore foram menos adaptados às dietas ricas em concentrado em relação aos Brangus.
\end{abstract}

Palavras-chave: bovino de corte, consumo, digestibilidade, concentrado

\begin{abstract}
The apparent digestibility of diets with 20, 40, 60 or 80\% of concentrate fed Brangus and Nellore steers was determined through total fecal collection. Eight animals, four of each breed, were used in two $4 \times 4$ Latin square design with five days of adaptation to the diets and five days of collection in each period. The initial age and body weight of Brangus and Nellore steers were 13 months and $248 \mathrm{~kg}$, and 30 months and $403 \mathrm{~kg}$, respectively. Concentrate levels affected $(P \leq 0.01)$ the digestibility coefficients of dry matter (DM), crude protein (CP), ether extract, crude fiber, neutral detergent fiber, nitrogen free extract (NFE), organic matter (OM) and total digestible nutrients (TDN). The diet with 80\% of concentrate showed higher DM, CP and TDN digestibilities. The digestibility of NFE, OM and the dry matter intake were different according to the breeds $(P<0.05)$. Brangus showed higher DM and TDN intake. The DM and TDN intake showed interaction $(P<0.01)$ breed by concentrate level, with higher intake for the Brangus at higher TDN diets. The Nellore steers were less adapted to diets rich in concentrate than Brangus steers.
\end{abstract}

Keywords: beef cattle, consumption, digestibility, concentrate

Recebido em 15 de março de 2005 Aceito em 21 de dezembro de 2006 E-mail: somarqputrino@uol.com.br Apoio: FAPESP 


\section{INTRODUÇÃO}

Para o estudo da nutrição animal, é importante conhecer a ingestão e a digestibilidade aparente das dietas fornecidas às diferentes raças de bovinos de corte e seus cruzamentos. Em trabalhos de pesquisa (Gonçalves et al., 1991; Oliveira et al., 1994), a raça Nelore, que compõe grande parte do rebanho brasileiro, é comparada a raças européias e mestiças quanto ao aproveitamento de dietas com diferentes níveis de concentrado.

A ingestão voluntária é determinante para o balanceamento de rações e para o estabelecimento de estratégias de alimentação que permita maior desempenho de bovinos (Nutrient..., 1996). A suplementação com energia ou proteína, geralmente, leva a uma queda no consumo de forragens, causando o chamado efeito de substituição (Lanna et al., 1998). Pesquisas comparativas entre Bos taurus taurus e Bos taurus indicus sugerem que há diferenças entre os dois grupos quanto à ingestão alimentar e eficiência de utilização de rações com alta ou baixa densidade de energia (Oliveira et al., 1994). Em zebuínos, o efeito de substituição parece ser mais intenso do que em taurinos, à medida que se aumenta a porcentagem de concentrados na dieta (Boin e Moura, 1977).

Segundo Dove (1996), o consumo pode ser limitado pela deficiência em proteína da ração. Em rações desbalanceadas, com baixa disponibilidade de compostos nitrogenados $(\mathrm{N})$ e ricas em fibra em detergente neutro (FDN), o suprimento de proteína degradável no rúmen (PDR) é o principal limitante para o crescimento microbiano. Em conseqüência, a digestão da parede celular fica comprometida e a ingestão de alimentos é reduzida.

O consumo e a digestibilidade de nutrientes podem estar correlacionados entre si, dependendo da qualidade da ração. Para rações de alta digestibilidade (acima de 66\%), ricas em concentrados (acima de 75\%) e com baixo teor de FDN (abaixo de 25\%), o consumo será menor quanto mais digestivo for o alimento e, em rações de baixa qualidade (acima de $75 \%$ de FDN), o consumo será maior quanto melhor for a digestibilidade do alimento (Van Soest, 1994; Mertens, 1994).
Revisando a literatura, Lanna et al. (1998) encontraram redução no desempenho esperado de zebuínos quando o nível de concentrado na dieta foi acima de $50 \%$ da matéria seca (MS) total. Segundo esses autores, os trabalhos sobre digestibilidade com zebuínos publicados no Brasil indicam que, por volta de $67 \%$ de NDT, a maior inclusão de concentrados na dieta parece não aumentar a digestibilidade ou $\mathrm{o}$ valor energético da dieta (a maior parte dos trabalhos indicados na revisão utilizava o milho como fonte de energia).

De acordo com Ledger et al. (1970), em rações com 40 e $60 \%$ de concentrados, foi verificado maior consumo, por unidade de peso vivo, em taurinos do que em zebuínos, e consumo intermediário em mestiços. Entretanto, Horrocks e Philips (1961) e Hunter e Siebert (1985) concluíram que não existe diferença entre zebuínos e taurinos na ingestão de matéria seca.

Geralmente, depressões na digestibilidade são resultantes da competição entre digestão e passagem. Um aumento significativo no consumo pode levar a uma maior taxa de passagem, reduzindo a digestibilidade (Fahey Jr. e Berger, 1988; Van Soest, 1994). Dessa forma, respostas positivas no consumo estão relacionadas a quedas na digestibilidade da dieta (Fahey Jr. e Berger, 1988).

O objetivo deste trabalho foi avaliar a digestibilidade aparente de dietas com 20, 40, 60 ou $80 \%$ de concentrado por animais das raças Brangus e Nelore, por meio da coleta total de fezes.

\section{MATERIAL E MÉTODOS}

O experimento foi realizado no Instituto de Zootecnia, em Nova Odessa, SP, e na Faculdade de Zootecnia e Engenharia de Alimentos FZEA / USP, Pirassununga, SP, com início em novembro de 2001.

Foram utilizados quatro novilhos da raça Nelore e quatro Brangus, alojados em gaiolas de metabolismo. A idade e o peso iniciais dos animais da raça Brangus e Nelore foram 13 meses e $248 \mathrm{~kg}$, e 30 meses e $403 \mathrm{~kg}$, respectivamente. O escore corporal dos animais era em torno de 4, numa escala de 1 a 9 (em que 1 são animais muito magros, e 9 muito gordos). Os animais receberam água e alimento ad libitum durante o período de adaptação de cinco dias, quando foram mensurados 
o alimento fornecido e as sobras. De acordo com o consumo durante o período de adaptação, o fornecimento foi ajustado de modo a não se obter sobra durante o período de coleta para evitar que o animal escolhesse a porção da ração que ingeria. A coleta de fezes foi realizada durante cinco dias consecutivos. A alimentação e a coleta das fezes foram realizadas no período da manhã. Os animais foram pesados no início de cada período de adaptação.
As rações experimentais (Tab. 1) foram compostas de $20,40,60$ e $80 \%$ de concentrado na matéria seca, e o volumoso utilizado foi a silagem de milho, com partículas de cerca de $2 \mathrm{~cm}$ e $35 \%$ de grãos. O milho seco utilizado foi moído em peneira grossa, na forma de quirera. As dietas foram formuladas no programa RLM ${ }^{\circledR}$ (ESALQ/USP) e conferidas pelo programa Cornell Net Carbohydrate and Protein System, desenvolvido por Fox et al. (1992).

Tabela 1. Ingredientes das rações experimentais (em porcentagem da matéria seca) para novilhos de corte

\begin{tabular}{lcccc}
\hline \multirow{2}{*}{ Ingrediente } & \multicolumn{3}{c}{ Porcentagem de concentrado na dieta (em base seca) } \\
\cline { 2 - 4 } & $20 \%$ & $40 \%$ & $60 \%$ & $80 \%$ \\
\hline Silagem de milho & 80,00 & 60,00 & 40,00 & 20,00 \\
Farelo de soja (49\% PB) & 10,050 & 8,699 & 7,979 & 7,716 \\
Milho grão seco & 6,952 & 27,910 & 48,101 & 67,977 \\
Uréia & 0,099 & 0,520 & 0,820 & 1,000 \\
Sulfato de amônia & 0,400 & 0,400 & 0,400 & 0,607 \\
Cloreto de potássio & 0,900 & 0,900 & 0,900 & 0,900 \\
Sal mineral & 0,600 & 0,600 & 0,600 & 0,600 \\
Calcáreo & 1,000 & 1,000 & 1,200 & 1,200 \\
Ionóforo (monensina) & 0,027 & 0,027 & 0,027 & 0,027 \\
\hline
\end{tabular}

Em cada dia de coleta, foi retirada uma amostra de fezes de cerca de $10 \%$ em relação ao total. Ao final de cada período de coleta, as amostras diárias foram misturadas e retirada uma nova amostra, correspondente a $10 \%$ do total, que foi analisada. O acondicionamento foi feito em sacos plásticos, e a conservação em freezer caseiro $\left(-18^{\circ} \mathrm{C}\right)$. No mesmo período de coleta das fezes, foi feita amostragem do alimento total oferecido e das sobras. As amostras do alimento e da sobra também foram congeladas até as análises.

Após o descongelamento, as amostras foram secas em estufa com circulação forçada de ar a $60^{\circ} \mathrm{C}$, durante 48 horas, sendo, posteriormente, moídas em peneira de $2 \mathrm{~mm}$, retirando-se uma subamostra para análise dos nutrientes: matéria seca (MS), proteína bruta (PB), fibra bruta $(\mathrm{FB})$, extrato etéreo (EE) e matéria mineral $(\mathrm{MM})$, conforme metodologia de Weende (Silva 1998). Também foram realizadas as análises de fibra em detergente neutro (FDN) e de fibra em detergente ácido (FDA), conforme metodologia de Van Soest (Silva, 1998). Na análise da FDN, não foram extraídos o nitrogênio e as cinzas.

Os valores do extrativo não nitrogenado (ENN) foram obtidos pela fórmula: $\mathrm{ENN}=\mathrm{MS}-(\mathrm{PB}+\mathrm{FB}+\mathrm{EE}+\mathrm{MM})$.
Para o cálculo dos nutrientes digestíveis totais (NDT), foi utilizada a fórmula:

NDT $(\%)=\% \mathrm{PBd}+\% \mathrm{FBd}+\% \mathrm{ENNd}+(\%$ EEd X 2,25), em que: $\mathrm{d}=$ porção digestível do nutriente.

A matéria orgânica (MO) foi determinada pela diferença entre a MS e a MM.

O delineamento experimental foi dois quadrados latinos $4 \times 4$ cada quadrado latino composto por uma raça. Os quatro animais de cada raça receberam dietas com quatro níveis de concentrados $(20,40$, 60 e $80 \%$ ), por quatro períodos. As análises estatísticas foram feitas com o pacote estatístico SAS (User's ..., 1989), através do Proc GLM. A análise de regressão foi feita para as variáveis que apresentaram diferença significativa a 1 ou $5 \%$ entre os níveis de concentrado na dieta.

O modelo matemático do delineamento experimental foi:

Yrtk $=\mu+\alpha r+\beta t+\gamma r t+$ ertk, em que:

Yrtk = observação;

$\mu=$ média geral;

$\alpha r=$ efeito de raça

$\beta \mathrm{t}=$ efeito do nível de concentrado

$\gamma \mathrm{rt}=$ efeito de interação raça versus nível de concentrado

ertk $=$ erro experimental 


\section{RESULTADOS E DISCUSSÃO}

A análise bromatológica da silagem de milho e dos concentrados das dietas é apresentada na Tab. 2.

O consumo de MS por dia em função da porcentagem de peso vivo foi diferente segundo os níveis de concentrado $(\mathrm{P}=0,055)$ e as raças $(\mathrm{P}<0,001)$, e observou-se interação concentrado versus raça $(\mathrm{P}=0,002)$. A raça Brangus apresentou maior consumo de MS em relação à Nelore (Fig. 1), e a análise de regressão indicou comportamento linear crescente $(\mathrm{P}=0,004)$ de acordo com o aumento na proporção dos níveis de concentrado na dieta. Para a raça Nelore, a análise de regressão indicou comportamento quadrático $(\mathrm{P}=0,005)$.

Tabela 2. Análise das rações experimentais (valores expressos em porcentagem da MS) para novilhos de corte

\begin{tabular}{lccccccc}
\hline & MS & PB & FB & EE & MM & FDN & FDA \\
\hline Silagem de milho & 30,86 & 7,83 & 24.89 & 2,40 & 4,37 & 59.12 & 34.36 \\
Concentrado 20\% & 89,59 & 34.95 & 3,96 & 2,50 & 12,41 & - & - \\
Concentrado 40\% & 89,04 & 23,15 & 3,55 & 3,44 & 6,23 & - & - \\
Concentrado 60\% & 89,01 & 19,15 & 3,73 & 3,56 & 4,76 & - & - \\
Concentrado 80\% & 88,60 & 17,74 & 3,38 & 3,75 & 4,21 & - & - \\
\hline
\end{tabular}

$\mathrm{MS}=$ matéria seca; $\mathrm{PB}=$ proteína bruta; $\mathrm{FB}=$ fibra bruta; $\mathrm{EE}=$ extrato etéreo; $\mathrm{MM}=$ matéria mineral; FDN = fibra em detergente neutro; FDA = fibra em detergente ácido.

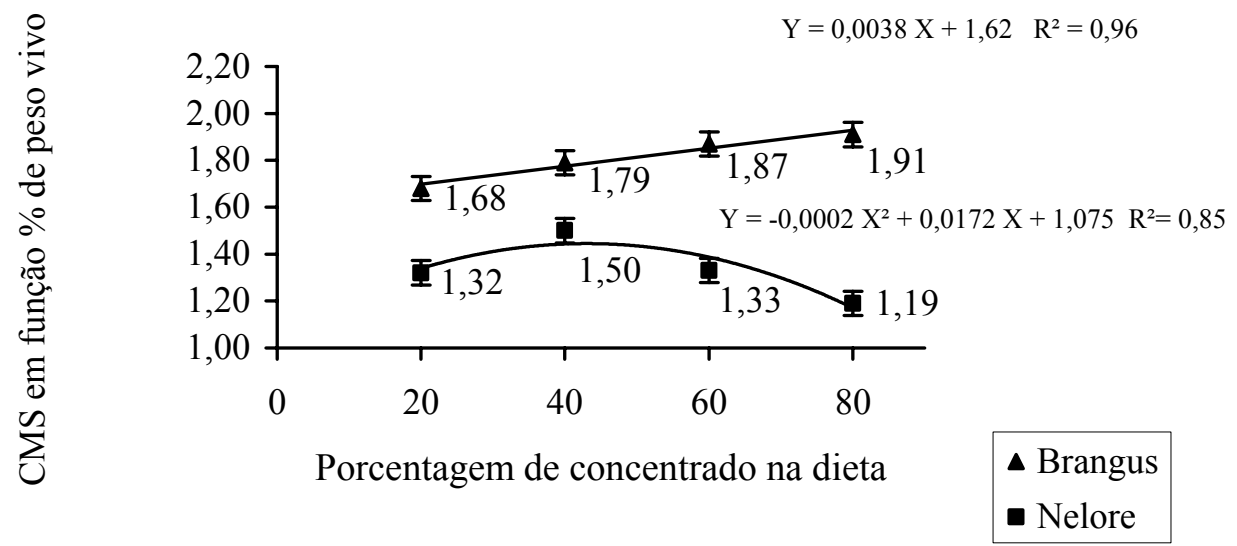

Figura 1. Consumo de matéria seca (CMS) em função da \% de peso vivo das raças Brangus e Nelore para as diferentes porcentagens de concentrado na dieta.

Cardoso et al. (2000) trabalharam com animais F1 Limousin $\times$ Nelore, alimentados com 25 a $75 \%$ de concentrado, e não observaram diferenças para o consumo em porcentagem do peso vivo, assim como Carvalho et al. (1997) que trabalharam com animais zebuínos alimentados com 20 e $70 \%$ de concentrado na dieta. Entretanto, Tibo et al. (2000) verificaram aumentos lineares de consumo de MS para animais F1 Simental $\times$ Nelore alimentados com 25 a $75 \%$ de concentrado, semelhante ao observado nos animais da raça Brangus deste experimento.
Oliveira et al. (1994) analisaram o consumo em porcentagem do peso vivo de animais de vários grupos genéticos e constataram tendência de menor consumo da raça Nelore quando comparada a animais mestiços, como neste trabalho. Segundo Galvão et al. (1991), o menor consumo alimentar de animais Nelore pode indicar menores exigências nutricionais associadas ao menor potencial de ganho de peso diário em relação aos mestiços.

A ingestão de NDT em função do peso vivo (CNDT), demonstrada na Fig. 2, apresentou diferença entre níveis de concentrado $(\mathrm{P}=0,002)$, entre raças $(\mathrm{P}<0,001)$ e interação entre os dois 
fatores $(\mathrm{P}=0,004)$. O comportamento dos níveis de concentrado para a raça Brangus pode ser explicado por um modelo de regressão linear simples
$(\mathrm{P}<0,01)$; no caso da raça Nelore, o comportamento não pode ser explicado por regressão linear, quadrática ou cúbica.

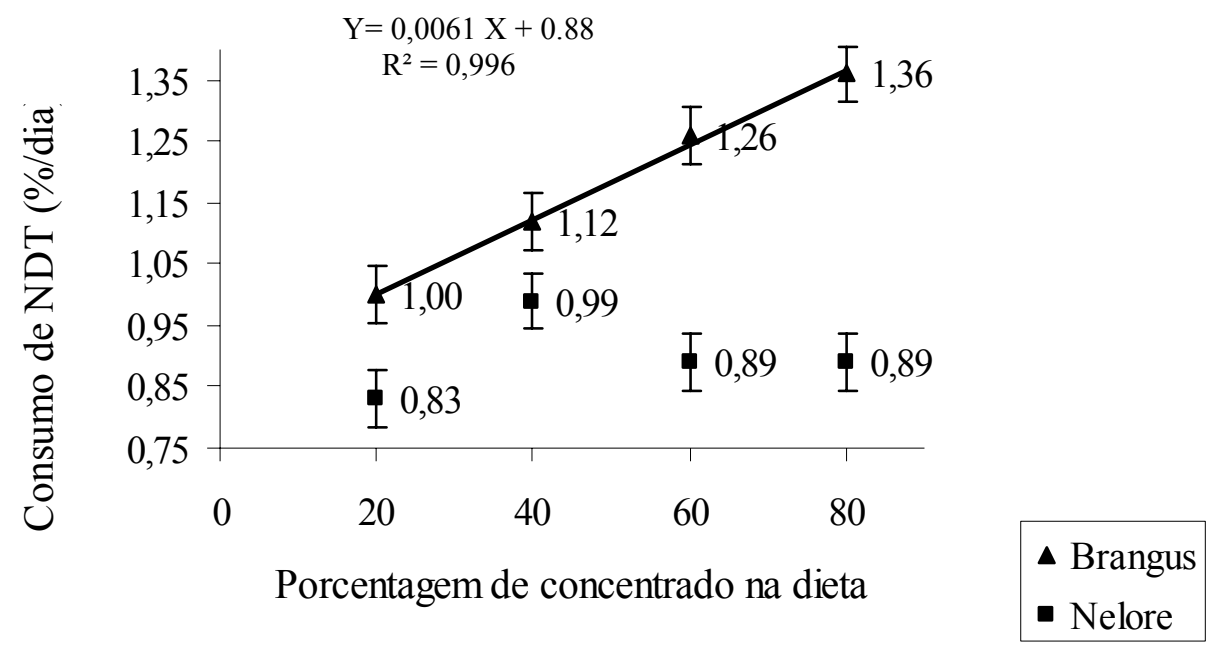

Figura 2. Consumo de nutrientes digestíveis totais (NDT) em função da \% de peso vivo para as diferentes porcentagens de concentrado na dieta para as raças Brangus e Nelore.

O consumo de NDT, assim como o de MS, foi maior para os animais da raça Brangus em relação à Nelore. Este resultado pode ser efeito da diferença de idade entre os animais. Quanto ao tratamento alimentar, as maiores médias foram obtidas com 80 e $40 \%$ de concentrado na dieta para os animais Brangus e Nelore, respectivamente, indicando que, neste experimento, a raça Brangus foi mais adaptada a dietas com elevada proporção de concentrado do que a Nelore.

Os animais da raça Nelore apresentaram queda no consumo a partir de $60 \%$ de concentrado na dieta (cerca de 67\% de NDT), resultado semelhante ao publicado por Lanna et al. (1998), ao citarem que a inclusão de concentrado acima de $67 \%$ de NDT para zebuínos não aumenta a digestibilidade da dieta, o que provavelmente influi no consumo.

Comparando a ingestão de NDT pelo Nelore em função da raça Brangus (Fig. 3), é possível observar que os menores valores foram obtidos com os tratamentos com 60 e $80 \%$ de concentrado, cujas reduções foram de 29,9 e $34,4 \%$, respectivamente.
A Tab. 3 contém os coeficientes de digestibilidade das rações experimentais.

Não houve interação entre nível de concentrado na dieta e raça para os parâmetros de digestibilidade avaliados. Para todos os coeficientes de digestibilidade que apresentaram diferença entre os níveis de concentrado na dieta e o NDT, a análise de regressão indicou comportamento linear, exceto para a FB, que apresentou comportamento cúbico.

Cardoso et al. (2000) também observaram acréscimos lineares na digestibilidade da MS, MO e PB de novilhos F1 Limousin $\times$ Nelore alimentados com 25 a $75 \%$ de concentrado na dieta. Entretanto, esses autores não encontraram influência dos níveis de concentrado sobre a digestibilidade da FDN, diferente deste trabalho em que se constatou comportamento linear decrescente com o acréscimo de concentrado na dieta.

Burger et al. (2000) verificaram efeito linear crescente na digestibilidade aparente da MS e $\mathrm{MO}$ ao variarem os níveis de concentrado (30 a $90 \%$ ) na dieta. Segundo Rode et al. (1985), os valores de digestibilidade da MS e MO elevaram-se à medida que aumentou o concentrado na dieta em virtude da redução de 
carboidratos estruturais e do aumento no teor de carboidratos não-estruturais na dieta. À medida que se eleva a proporção de concentrado na dieta, elevam-se os coeficientes de digestibilidade da MS, MO e energia bruta (EB) (Lima, 1986).

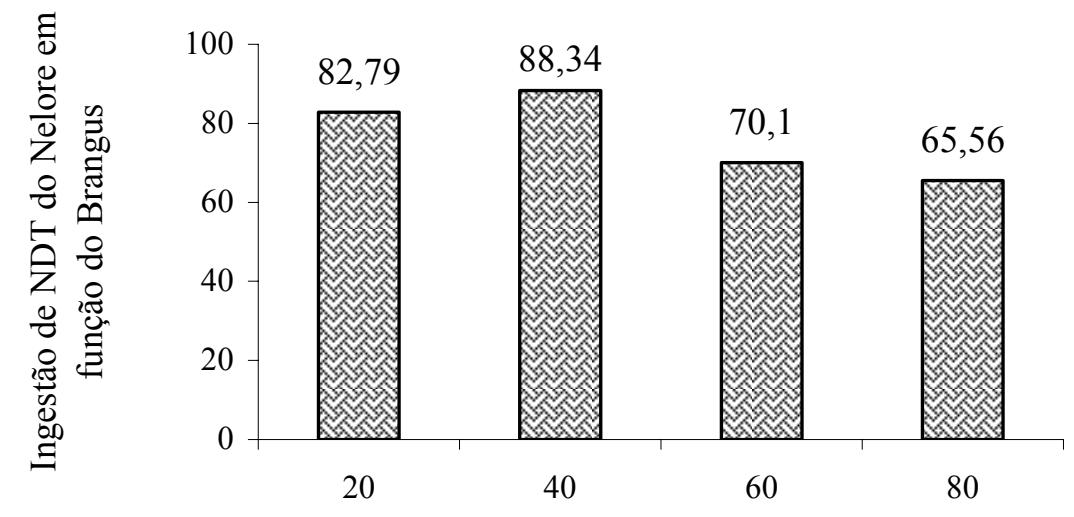

Níveis de concentrado na dieta (\%)

Figura 3. Ingestão de nutrientes digestíveis totais (NDT) do Nelore como porcentagem da ingestão do Brangus para os diferentes níveis de concentrado.

Tabela 3. Coeficiente de digestibilidade das rações com 20, 40, 60 ou $80 \%$ de concentrado para animais das raças Brangus e Nelore

\begin{tabular}{|c|c|c|c|c|c|c|c|c|c|}
\hline \multirow{2}{*}{ Item } & \multicolumn{4}{|c|}{ Nível de concentrado } & \multicolumn{2}{|c|}{ Raça } & \multicolumn{3}{|c|}{ Valor de $\mathrm{P}$} \\
\hline & $20 \%$ & $40 \%$ & $60 \%$ & $80 \%$ & Brangus & Nelore & $\mathrm{C}$ & $\mathrm{R}$ & $\mathrm{RxC}$ \\
\hline Matéria seca (\%) & 62,70 & 63,61 & 66,49 & 70,94 & 66,87 & 65,01 & 0,002 & 0,199 & 0,653 \\
\hline Proteína bruta $(\%)$ & 69,32 & 72,30 & 73,53 & 79,19 & 74,24 & 72,93 & $<0,01$ & 0,172 & 0,245 \\
\hline Extrato etéreo (\%) & 63,10 & 64,62 & 63,29 & 72,60 & 67,16 & 64,65 & 0,077 & 0,377 & 0,328 \\
\hline Fibra bruta $(\%)$ & 66,97 & 70,67 & 62,05 & 62,76 & 65,36 & 65,87 & 0,010 & 0,781 & 0,710 \\
\hline Fibra em detergente neutro (\%) & 57,93 & 54,64 & 49,62 & 46,74 & 53,86 & 50,59 & 0,007 & 0,143 & 0,793 \\
\hline Fibra em detergente ácido(\%) & 52,14 & 54,30 & 50,45 & 49,91 & 51,35 & 52,05 & 0,466 & 0,741 & 0,657 \\
\hline Matéria mineral (\%) & 46,47 & 44,03 & 50,38 & 57,51 & 46,61 & 52,58 & 0,010 & 0,036 & 0,903 \\
\hline Extrativo não-nitrogenado (\%) & 65,14 & 64,16 & 69,95 & 73,01 & 69,97 & 66,16 & 0,007 & 0,047 & 0,308 \\
\hline Matéria orgânica (\%) & 66,02 & 67,02 & 69,56 & 73,54 & 70,43 & 67,64 & 0,003 & 0,046 & 0,473 \\
\hline Nutrientes digestíveis totais (\%) & 61,43 & 64,10 & 67,05 & 73,04 & 67,63 & 65,18 & $<0,01$ & 0,086 & 0,512 \\
\hline
\end{tabular}

$\mathrm{C}=$ nível descritivo do teste $\mathrm{F}$ para o fator níveis de concentrado na dieta, $\mathrm{R}=$ nível descritivo do teste $\mathrm{F}$ para o fator raças, $\mathrm{RxC}=$ nível descritivo do teste $\mathrm{F}$ para a interação.

Resende et al. (2001), trabalhando com novilhos mestiços alimentados com dietas com 15 a $75 \%$ de concentrado na dieta, observaram efeito quadrático para a digestibilidade da $\mathrm{MS}, \mathrm{MO}$, FDN, PB e EB.

Lançanova et al. (2001) forneceram dietas com $55 \%$ de concentrado a animais de diferentes grupos genéticos (Gir, Nelore, Guzerá, Santa Gertrudes e Caracu) e avaliaram os coeficientes de digestibilidade dos nutrientes por meio de coleta total de fezes. As digestibilidades de MS, $\mathrm{MO}$, EB e NDT foram semelhantes entre os grupos genéticos. Lorenzoni et al. (1986) citaram que existe semelhança entre zebuínos e taurinos em relação à digestibilidade da MS e EB. Essa semelhança foi observada para os animais das raças Brangus e Nelore, exceto MM, ENN e MO.

O maior coeficiente de digestibilidade da PB foi para a dieta com maior proporção de concentrado, o que também foi observado por Lima (1986). Segundo Dias (1999), aumentos lineares na digestibilidade de PB e EE com o aumento dos níveis de concentrado na dieta ocorrem devido ao aumento no consumo desses nutrientes. 
Rodriguez et al. (1997) não encontraram diferenças entre animais Bos taurus taurus (Holandês) e Bos taurus indicus (Nelore) para a digestibilidade da PB. Segundo esses autores, a grande controvérsia na literatura quanto à digestibilidade da proteína entre grupos genéticos pode estar associada a fatores como características das rações utilizadas, níveis de consumo, entre outros.

Para a FDN, o decréscimo linear observado é explicado pelo efeito depressor do concentrado sobre a digestibilidade da fibra (Resende et al., 2001). Araújo et al. (1998) encontraram resultados semelhantes fornecendo dietas com 10 a $90 \%$ de concentrado. Burger et al. (2000) e Berchielli (1994) não verificaram efeitos dos níveis de concentrado sobre a digestibilidade da FDN.

Para a FDA, Araújo et al. (1998) observaram efeito quadrático dos níveis de concentrado sobre a digestibilidade, sendo o valor máximo obtido quando foram fornecidos $29 \%$ de concentrado na dieta. Entretanto, assim como neste trabalho, Rodriguez et al. (1996), também, não observaram diferenças na digestibilidade da FDA.

A porcentagem de NDT foi maior para o tratamento contendo $80 \%$ de concentrado. Quanto ao efeito de raças sobre o NDT, a Brangus apresentou tendência $(\mathrm{P}=0,09)$ de maior digestibilidade do que a Nelore.

\section{CONCLUSÕES}

A raça Brangus apresentou consumo linear crescente em função do aumento de concentrado na dieta, enquanto a raça Nelore apresentou queda a partir de $60 \%$ de concentrado. Isso pode ser indicativo da menor adaptação às dietas ricas em concentrado, à base de milho, pelos animais Nelores em relação aos Brangus. Quanto à diferença de consumo de alimento entre as raças, esta pode ter ocorrido em função da diferença de idade entre os animais avaliados. $\mathrm{O}$ fornecimento de $80 \%$ de concentrado na dieta aumentou a porcentagem de NDT em relação aos níveis de $20 \%, 40 \%$ e $60 \%$ de concentrado.

\section{REFERÊNCIAS BIBLIOGRÁFICAS}

ARAÚJO, G.G.L.; COELHO da SILVA, J.F.; VALADARES FILHO, S.C. et al. Consumo e digestibilidade total dos nutrientes de dietas contendo diferentes níveis de volumoso, em bezerros. Rev. Bras. Zootec., v.27, p.345-354, 1998.

BERCHIELLI, T.T. Efeito da relação volumoso:concentrado sobre a partição da digestão, a sintese de proteína microbiana, produção de ácidos graxos voláteis e o desempenho de novilhos em confinamento. 1994. 104f. Tese (Doutorado em Ciência Animal) Escola de Veterinária, Universidade Federal de Minas Gerais, Belo Horizonte.

BOIN, C.; MOURA, M.P. Comparação entre dois níveis de proteína bruta e entre dois níveis de energia para zebuínos em crescimento. Bol. Ind. Anim., v.34, p.155-163, 1977.

BURGER, P.J.; PEREIRA, J.C.; COELHO da SILVA, J.F. et al. Consumo e digestibilidade aparente total e parcial em bezerros holandeses alimentados com dietas contendo diferentes níveis de concentrado. Rev. Bras. Zootec., v.29, p.206-214, 2000.

CARDOSO, R.C.; VALADARES FILHO, S.C.; COELHO da SILVA, J.F. et al. Consumo e digestibilidades aparentes totais e parciais de rações contendo diferente níveis de concentrado, em novilhos fl Limousin $\times$ Nelore. Rev. Bras. Zootec., v. 29, p.1832-1843, 2000.

CARVALHO, A.U.; VALADARES FILHO, S.C.; COELHO da SILVA, J.F. et al. Níveis de concentrado em dietas de zebuínos. 1. Consumo e digestibilidade aparente. Rev. Bras. Zootec., v.26, p.986-995, 1997.

DIAS, H.L.C. Consumo, digestibilidades aparentes totais e parciais de dietas contendo diferentes niveis de concentrado, em novilhos F1 Limousin $\times$ Nelore. 1999. 76f. Dissertação (Mestrado em Zootecnia) - Universidade Federal de Viçosa, Viçosa, 1999.

DOVE, H. The ruminant, the rumen and the pasture resource: nutrient interactions in the grazing animal. In: HODGSON, J.; ILLUS, A. W. (Eds). The ecology and management of grazing systems: CAB Internacional, 1996. p.219-246. 
FAHEY Jr., G.C.; BERGER, L.L. Carbohydrate nutrition of ruminants. In: CHURCH, D.C. (Ed.). The ruminant animal: digestive physiology and nutrition. New Jersey: Prentice Hall, 1998. p.269297.

FOX, D.G.; SNIFFEN, C.J.; O'CONNOR, J.D. et al. Search: agriculture. Ithaca: Cornell University, Agriculture Experimental Station, n.34, 1992. 128p.

GALVÃO, J.G.; FONTES, C.A.A.; PIRES, C.C. et al. Ganho de peso, consumo e conversão alimentar em bovinos não-castrados, de três grupos raciais, abatidos em diferentes estádios de maturidade (estudo I). Rev. Soc. Bras. Zootec., v.20, p.494-501, 1991.

GONÇALVES, L.C.; SILVA, J.F.C.; ESTEVÃO, M.M. et al. Consumo e digestibilidade da matéria seca e da energia em zebuínos e taurinos, seus mestiços e bubalinos. Rev. Soc. Bras. Zootec., v.20, p.384-395, 1991.

HORROCKS, D.; PHILLIPS, G.D. Factors affecting the water and food intakes of European and zebu-type cattle. J. Agric. Sci., v.56, p.379-381, 1961.

HUNTER, R.A.; SIEBERT, B.D. Utilization of low-quality roughage by Bos taurus and Bos indicus cattle. 1- Rumen digestion. Br. J. Nutr., v.53, p.637-648, 1985.

LANÇANOVA, J.A.C.; OLIVEIRA, M.D.S.; PACOLA, L.J. et al. Digestibilidade aparente da matéria seca, matéria orgânica, e energia bruta e nutrientes digestíveis totais de uma ração completa para bovinos de diferentes grupos genéticos. Rev. Bras. Zootec., v. 30, p.897-903, 2001.

LANNA, D.P.D.; FOX, D.G.; TEDESCHI, L.O. Exigências nutricionais de gado de corte: $\mathrm{O}$ sistema NRC. In: SIMPÓSIO SOBRE PRODUÇÃO INTENSIVA GADO CORTE, 1998, Campinas. Anais...Campinas: CBNA, 1998. p.138-167.

LEDGER, H.P.; ROGERSON, A.; FREEMAN, G.H. Further studies on the voluntary food intake of Bos indicus, Bos taurus and crossbred cattle. Anim. Prod., v.12, p.425-431, 1970.

LIMA, F.C. Digestão total e parcial de energia e proteina em taurinos, zebuínos, seus mestiços e em bubalinos. 1986. 120f. Tese. (Doutorado em Zootecnia) - Universidade Federal de Viçosa, Viçosa, MG.

LORENZONI, W.R.; CAMPOS, J.; GARCIA, J.A. et al. Ganho de peso, eficiência alimentar e qualidade da carcaça de novillos búfalos, nelores, holandeses e mestiços holandês-zebu. Rev. Bras. Zootec., v.15, p.486-497, 1986.

MERTENS, D.R. Regulation of forage intake. In: FAHEY Jr., G.C. (Ed.). Forage quality, evaluation and utilization. Madison: American Society of Agronomy, 1994. p.450-493.

NUTRIENT requirements of beef cattle. 7.ed. Washington: NRC, 1996. 242p.

OLIVEIRA, M.A.T.; FONTES, C.A.A.; LANA, R.P. et al. Consumo alimentar e digestibilidade de rações com dois níveis de concentrado em bovinos de cinco grupos genéticos. Rev. Soc. Bras. Zootec., v.23, p.667-677, 1994.

RESENDE, F.D.; QUEIROZ, A.C.; OLIVEIRA, J.V. et al. Bovinos mestiços alimentados com diferentes proporções de volumoso:concentrado. 1 . Digestibilidade aparente dos nutrientes, ganho de peso e conversão alimentar. Rev. Bras. Zootec., v.30, p.261-269, 2001.

RODE, L.M.; WEAKLEY, D.C.; SATTER, L.D. Effect of forage amount and particle size in diets of lactating dairy cows on site of digestion and microbial synthesis. Can. J. Anim. Sci., v.65, p.101111, 1985.

RODRIGUEZ, L.R.R.; FONTES, C.A.A.; JORGE, A.M., et al. Consumo de rações contendo quatro níveis de concentrado por bovinos holandeses e nelore e por bubalinos. Rev. Soc. Bras. Zootec., v.25, p.568-581, 1996.

RODRIGUEZ, L.R.R.; FONTES, C.A.A.; JORGE, A.M. et al. Digestibilidade de rações contendo quatro níveis de concentrado, em bovinos (taurinos e zebuínos) e bubalinos. Rev. Bras. Zootec., v. 26, p.844-851, 1997.

USER'S guide: statistics. Version 6. Cary, NC: SAS Institute, 1989.

SILVA, D.J. Análise de alimentos: métodos químicos e biológicos. Viçosa: UFV, 1998. 166p.

TIBO, G.C.; VALADARES FILHO, S.C.; VALADARES, R.F.D. et al. Níveis de concentrado em dietas de novilhos mestiços F1 Simental $\times$ Nelore. 1. Consumo e digestibilidades. Rev. Bras. Zootec., v. 29, p.910-920, 2000.

VAN SOEST, P.J. Nutritional ecology of the ruminants. 2.ed. London: Comstock Publishing Associates, 1994. 4476p. 